\title{
The effect of maternal hypothermic cardiopulmonary bypass on fetal lamb temperature, hemodynamics, oxygenation, and acid-base balance
}

\author{
Giorgio Pardi, MD \\ Maria M. Ferrari, MD \\ Fiore lorio, $M D^{\mathrm{b}}$ \\ Fabio Acocella, DVM, PhD \\ Veronica Boero, MDa \\ Nicola Berlanda, $\mathrm{MD}^{\mathrm{a}}$ \\ Ario Monaco, DVM ${ }^{\mathrm{C}}$ \\ Claudio Reato, $\mathrm{MD}^{\mathrm{a}}$ \\ Francesco Santoro, MD \\ Irene Cetin, $\mathrm{MD}^{\mathrm{a}}$
}

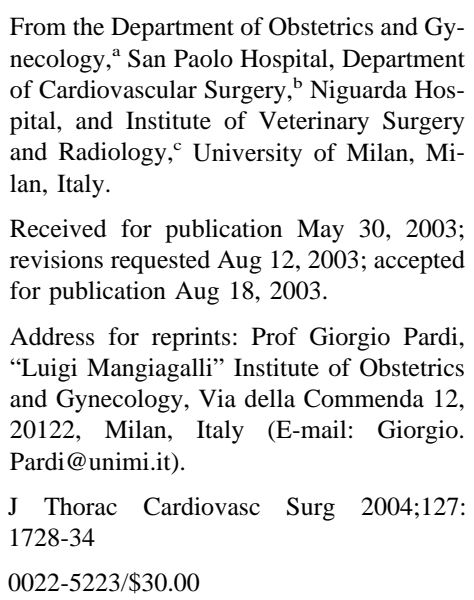

Copyright ( $\odot 2004$ by The American Association for Thoracic Surgery

doi:10.1016/j.jtcvs.2003.08.036
Objective: To evaluate fetal-maternal temperature relationship and fetal cardiovascular and metabolic response during maternal hypothermic cardiopulmonary bypass in pregnant ewes.

Methods: Cardiopulmonary bypass was instituted in 9 pregnant ewes, reaching 2 different levels of maternal hypothermia: $24^{\circ} \mathrm{C}$ to $20^{\circ} \mathrm{C}$ (deep hypothermia) in group A (5 cases) and less than $20^{\circ} \mathrm{C}$ (very deep hypothermia) in group B (4 cases). Hypothermic levels were maintained for 20 minutes, then the rewarming phase was started. Fetal and maternal temperature, blood pressure, heart rate, electrocardiogram, blood gases, and acid-base balance were evaluated at different levels of hypothermia and during recovery.

Results: Fetal survival was related to maternal hypothermia: all group A fetuses survived, while 2 of 4 fetuses of group B in which maternal temperature was lowered below $18^{\circ} \mathrm{C}$ died in a very deep acidotic and hypoxic status. Maternal temperature was always lower than fetal temperature during cooling; during rewarming the gradient was inverted. The start of cardiopulmonary bypass and cooling was associated with transient fetal tachycardia and hypertension; then, both fetal heart rate and blood pressure progressively decreased. The reduction of fetal heart rate was of 7 beats per minute for each degree of fetal cooling. Deep maternal hypothermia was associated with fetal alkalosis and reduction of $\mathrm{Po}_{2}$. Very deep hypothermia, in particular below $18^{\circ} \mathrm{C}$, caused irreversible fetal acidosis and hypoxia.

Conclusions: Deep maternal hypothermic cardiopulmonary bypass was associated with reversible modifications in fetal cardiovascular parameters, blood gases, and acid-base balance and therefore with fetal survival. On the contrary, fetuses did not survive to a very deep hypothermia below $18^{\circ} \mathrm{C}$.

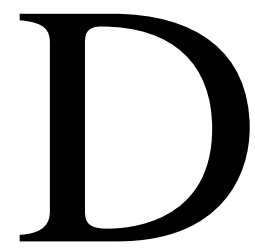

uring pregnancy, women with heart disease, even if well compensated, are at risk of acute heart failure because of the increased cardiorespiratory requirements associated with pregnancy. ${ }^{1}$ When emergency cardiovascular surgery is required during pregnancy, some anesthesiological and cardiorespiratory techniques can compromise feto-placental vascularization and function. In particular, hypothermia, hemodilution, inhibition of coagulation, and lack of arterial pulse can 
cause important modifications of placental perfusion and intervillous blood flow with dramatic consequences on fetal well-being. ${ }^{2-6}$

The largest series reported of cardiovascular surgery with the use of cardiopulmonary bypass (CPB) in pregnant women ${ }^{4,7,8}$ showed a very high fetal mortality (20\%-29\%) and morbidity (7\%-9\%), especially related to the length of the surgical procedures and the use of hypothermia. ${ }^{4,9}$ The effect of maternal hypothermic CPB on human fetal metabolism and hemodynamics, however, is still poorly understood due to the impossibility of performing fetal invasive monitoring during cardiovascular operations.

The available data on human fetuses, recorded by external cardiotocography, only concern the modifications of fetal heart rate and the onset of irreversible uterine contractions, which are considered the most important predictors of fetal death. ${ }^{9}$

Experimental animal studies on the effect of maternal hypothermia on uterine circulation and fetal survival concluded that maternal hypothermia causes a decrease in placental blood flow with increased vascular resistances; however, very little information is reported about fetal cardiovascular and metabolic changes. ${ }^{10-12}$

The aim of this study was to evaluate the effect of different levels of maternal hypothermic CPB on fetal lamb temperature, hemodynamics, and metabolism using a continuous invasive monitoring under acute conditions.

\section{Materials and Methods}

The studies were performed in the Center of Experimental Fetal Surgery of the University of Milan. All animals received veterinary care in compliance with Italian guidelines for the care and use of laboratory animals.

\section{Selection of Animals}

The study population consisted of 9 bergamasque ewes carrying twin pregnancies. Transabdominal ultrasound was used to determine the number of the fetuses as well as the gestational age according to the measurement of the fetal biparietal diameter and the abdominal circumference. ${ }^{13}$ Four ewes near term of pregnancy (gestational age 130-135 days; term of gestation 145 days) and 5 preterm (gestational age 100-115 days) were selected.

\section{Maternal Procedures and Cardiopulmonary Bypass}

Pregnant ewes were studied under acute conditions. After 36 hours of fasting all animals underwent endotracheal general anesthesia in lithotomic position. Maternal electrocardiogram (ECG), heart rate, and blood pressure were recorded continuously. Blood samples for biochemical analysis were obtained from femoral artery and temperature was monitored through an endoesophageal thermistor. After cannulation of the carotid artery and external jugular vein a conventional $\mathrm{CPB}$ was instituted using a roller pump and hollow fibers oxygenating system. A non-blood priming was used to obtain a hematocrit of about $20 \%$. Care was observed to keep a pump flow of $4 \mathrm{~L}$ per minute to avoid a drop in arterial pressure below $40 \mathrm{~mm} \mathrm{Hg}$. The hematocrit and actual blood flow utilized are those commonly used when CPB is applied in our clinical practice. Cooling was started when stable conditions of the mother were reached and no measures were taken to correct the natural $\mathrm{pH}$ tendency to alkalosis during cooling (alpha stat-strategy). ${ }^{14}$

The animals were divided into 2 groups: in the first group (group A), including 2 near-term and 3 preterm ewes, the maternal temperature was lowered to $24^{\circ} \mathrm{C}$ to $20^{\circ} \mathrm{C}$ (deep hypothermia); in the second group (group B), including 2 near-term and 2 preterm ewes, a very deep hypothermia of less than $20^{\circ} \mathrm{C}$ was obtained. Mean maternal cooling velocity was $0.5^{\circ} \mathrm{C} / \mathrm{min}$. Once the established level of hypothermia was reached, the temperature was maintained constant for 20 minutes. Then, the rewarming phase was started. In case of fetal survival, maternal extracorporeal circulation was maintained for about 1 hour (recovery phase). After completion of the studies, animals were killed by intravenous injection of chloride potassium.

\section{Fetal Procedures}

After induction of maternal anesthesia, a $20-\mathrm{cm}$ midline maternal laparotomy was performed and 1 uterine horn was exposed; the fetal head of 1 of the 2 fetuses, previously localized with ultrasound, was manually fixed against the miometrium. The uterus and the membranes were incised and fetal head and neck were gently extracted, taking care to avoid the amniotic fluid leakage. An endoesophageal electrode was positioned for the morphological analysis of fetal ECG (STAN prototype; Neoventa, Goteborg, Sweden) and for continuous fetal heart rate (FHR) recording (Sonicaid Meridian 800; Oxford Instrument, Oxford, United Kingdom). The STAN instrument ${ }^{15}$ provides an automatic measurement of changes in ST waveforms and T/QRS ratio averaging 30 consecutive ECG complexes and allows the analysis of the duration of the electrical cardiac phenomena. An endoesophageal thermistor was inserted for continuous recording of temperature and the carotid artery was cannulated with a G24 over-the-needle catheter for blood pressure recording (monitor Kontron Medical 108; Glasgow, United Kingdom) and blood sampling. The fetal head was then repositioned into the uterine cavity and membranes and miometrium were sutured as well as the abdominal wall. Doppler velocimetry of the umbilical artery blood flow, an indirect measure of placental vascular resistances, ${ }^{16}$ was measured with a coaxial pulsed Doppler velocimeter (AU5 Esaote; Genova, Italy) and the pulsatility index (PI) was calculated according to the simplified Gosling formula (systolic velocity minus diastolic velocity divided by mean velocity). ${ }^{16}$

The noninstrumented fetus was not extracted from the uterus and FHR and umbilical artery PI were periodically recorded through an external ultrasound. Figure 1 shows the maternal and fetal instrumentation.

\section{Maternal and Fetal Blood Analysis}

The following parameters were analyzed in both maternal and fetal arterial blood, (ABL 735 Radiometer, Copenhagen, Denmark): $\mathrm{pH}, \mathrm{Po}_{2}(\mathrm{~mm} \mathrm{Hg}), \mathrm{Hb}$ saturation $\left(\mathrm{Hb}\right.$ Sat \%), $\mathrm{PCO}_{2}(\mathrm{~mm} \mathrm{Hg})$, $\mathrm{HCO}_{3}(\mathrm{mmol} / \mathrm{L})$, base excess $(\mathrm{mmol} / \mathrm{L})$, lactate $(\mathrm{mmol} / \mathrm{L})$, plasma electrolytes $(\mathrm{Na}, \mathrm{K}, \mathrm{Cl}$ ). Biochemical measurements were obtained with correction for the actual temperature of each sample. 


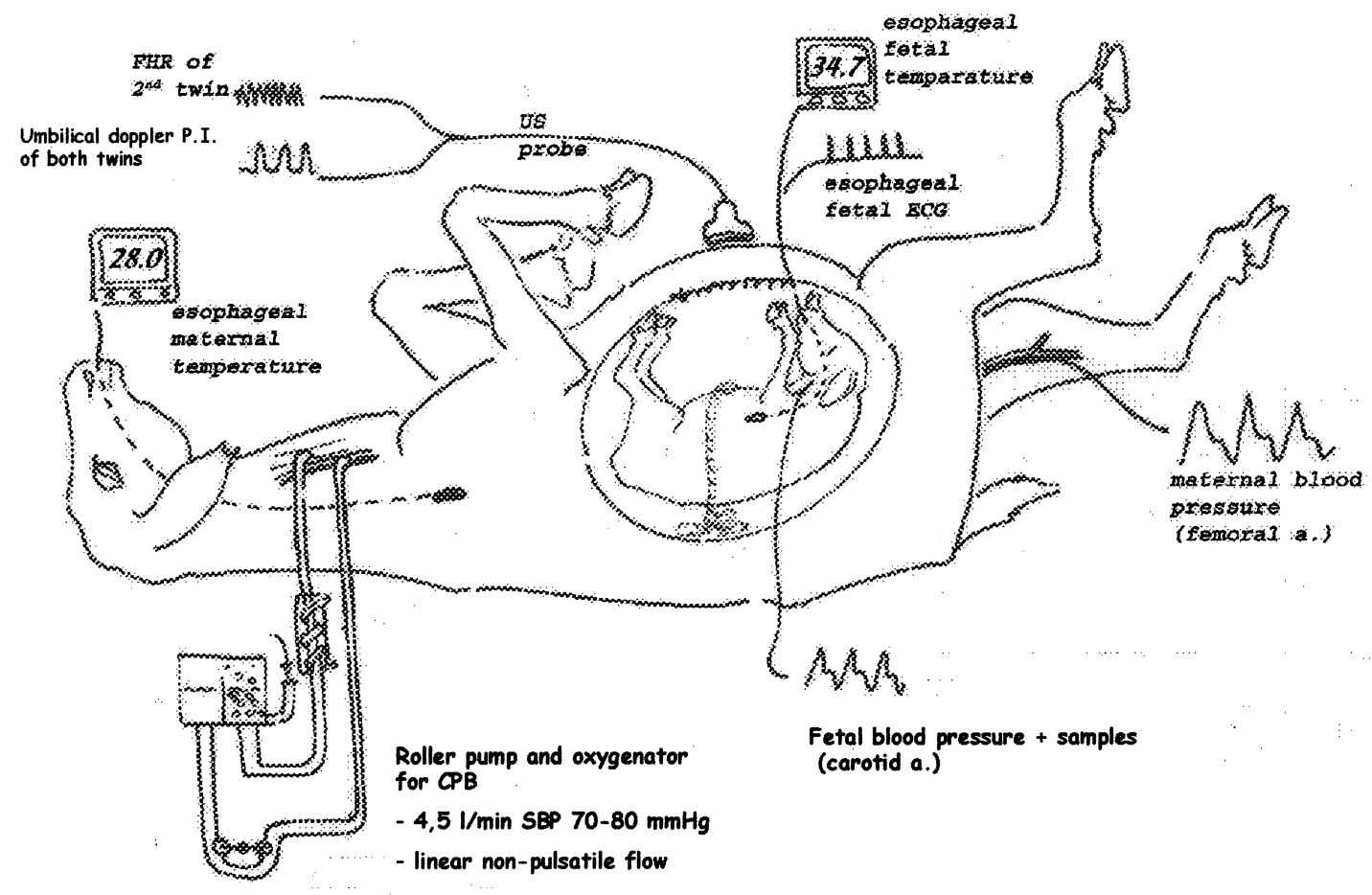

Figure 1. Maternal and fetal instrumentation.

TABLE 1. Fetal survival at different gestational ages related to the degree of fetal and maternal hypothermia

\begin{tabular}{lcccc}
\hline Experiment & $\begin{array}{c}\text { Minimal } \\
\text { maternal } \\
\text { temperature } \\
\left({ }^{\circ} \mathbf{C}\right)\end{array}$ & $\begin{array}{c}\text { Minimal fetal } \\
\text { temperature } \\
\left({ }^{\circ} \mathbf{C}\right)\end{array}$ & $\begin{array}{c}\text { Gestational } \\
\text { age (d) }\end{array}$ & $\begin{array}{c}\text { Fetal } \\
\text { survival }\end{array}$ \\
\hline $\begin{array}{c}\text { Group A } \\
0141\end{array}$ & 24 & 30 & 100 & Yes \\
0070 & 24 & 31 & 135 & Yes \\
0031 & 22 & 30 & 135 & Yes \\
0121 & 20 & 26 & 110 & Yes \\
0161 & 20 & 25 & 105 & Yes \\
Group B & & & & \\
0142 & 18 & 28 & 100 & Yes \\
0132 & 18 & 27 & 135 & Yes \\
0151 & 13 & 21 & 130 & No \\
0111 & 12 & 22 & 115 & No \\
\hline
\end{tabular}

Group $\mathrm{A}$, Deep hypothermia $\left(20^{\circ} \mathrm{C}-24^{\circ} \mathrm{C}\right)$; group $\mathrm{B}$, very deep hypothermia $\left(<20^{\circ} \mathrm{C}\right)$.

\section{Results}

Fetal and Maternal Survival

Table 1 shows fetal survival according to the degree of hypothermia. All 5 fetuses that underwent deep hypothermia (group A) and 2 of 4 fetuses that underwent very deep hypothermia (group B) were alive at the end of the procedure. In the 2 fetuses that did not survive, maternal temperature was lowered below $18^{\circ} \mathrm{C}$ and fetal temperature was below $25^{\circ} \mathrm{C}$; these fetuses died after a prolonged period of bradycardia, despite the maternal rewarming. No differences were observed between term and preterm fetuses. All maternal ewes were alive at the completion of the studies.

\section{Feto-Maternal Temperature Relationship}

Fetal temperature was always higher than maternal temperature before and during cooling, determining a positive feto-maternal gradient of temperature. As shown in Figure 2, mean feto-maternal gradient has a triphasic behavior during cooling. First, it increases from $+1{ }^{\circ} \mathrm{C}$ at basal temperature to $+7^{\circ} \mathrm{C}$ at $30^{\circ} \mathrm{C}$ of maternal temperature, then remains stable between $30^{\circ} \mathrm{C}$ and $20^{\circ} \mathrm{C}$ of maternal temperature, and finally increases to more than $10^{\circ} \mathrm{C}$ below $20^{\circ} \mathrm{C}$ of maternal temperature. Figure 3 shows the relationship between maternal and fetal temperature in 2 cases of fetal survival (Exp 0141, Exp 0131) and in one case of fetal death (Exp 0111). During the rewarming phase the gradient was inverted: fetal increase of temperature followed the mother's warming.

\section{Maternal and Fetal Cardiovascular Modifications}

Maternal cardiovascular modifications during cooling and rewarming consisted of a progressive decrease of heart rate until a complete stop of cardiac activity at $20^{\circ} \mathrm{C}$ to $18^{\circ} \mathrm{C}$ and a return to basal heart rate with rewarming. Blood pressure was never lower than $40 \mathrm{~mm} \mathrm{Hg}$ during CPB. 

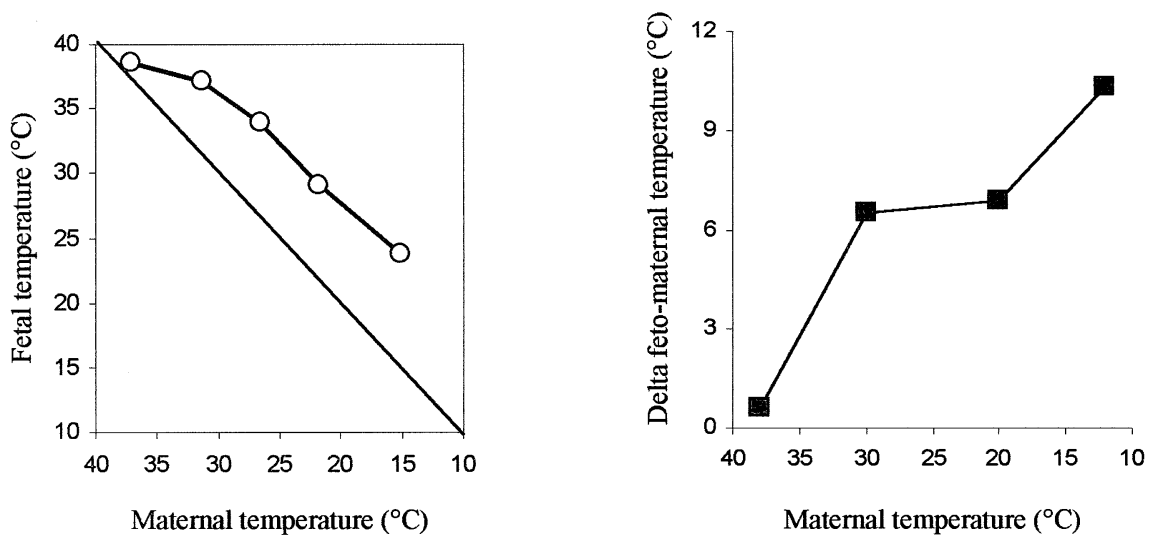

Figure 2. Fetal temperature (left) and fetal-maternal gradient (right) are plotted against maternal temperature.

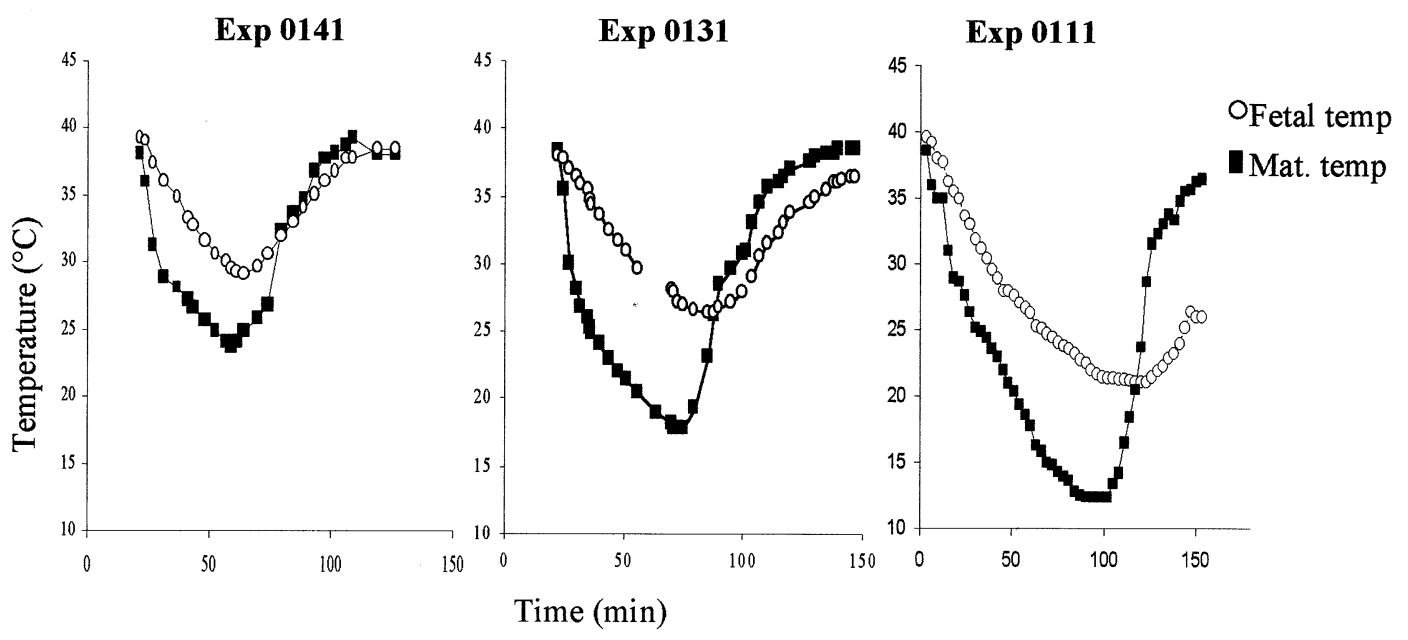

Figure 3. Feto-maternal temperature curves during cooling and rewarming in case of fetal survival (Exp 0141, 0131) and death (Exp 0111).

In the fetus, the start of $\mathrm{CPB}$ and cooling was associated with transient tachycardia and hypertension; then, both FHR and blood pressure progressively decreased (Figure 4). The average reduction of FHR was of 7 beats per minute (bpm) for each degree of fetal cooling. In the fetuses that survived, fetal heart rate rapidly increased during the rewarming phase, coming back to basal values.

During cooling, fetal ECG showed modifications of ST interval with prolongation of QT interval and progressive increase of $\mathrm{T}$ wave amplitude (Figure 5). Extrasystolic bigeminism appeared in 3 cases at about $30^{\circ} \mathrm{C}$ of fetal temperature (Figure 6). Modification of ventricular depolarization phases, such as the appearance of "J" wave typical of hypothermia, ${ }^{17}$ did not systematically appear. During rewarming, fetal ECG morphology returned to basal appearance (Figure 5).

No significant differences were detected in umbilical artery PI measured during the different steps of the studies.
Fetal and Maternal Blood Gases and Acid-Base

\section{Balance}

Fetal $\mathrm{pH}$, blood gases, lactate, and plasma electrolytes in the two groups are presented in Table 2. During the cooling phase in group A fetal $\mathrm{pH}$ increased from 7.34 to 7.39 , fetal $\mathrm{Po}_{2}$ decreased from $21.7 \mathrm{~mm} \mathrm{Hg}$ to $13.6 \mathrm{~mm} \mathrm{Hg}(P=.002)$ and $\mathrm{Hb}$ saturation remained stable at $59 \%$. In the fetuses of group B that survived, fetal $\mathrm{pH}$ further increased to 7.44, $\mathrm{PO}_{2}$ significantly decreased to $8.2 \mathrm{~mm} \mathrm{Hg}(P=.001)$, and $\mathrm{Hb}$ saturation decreased to $44 \%(P=.04)$; in the 2 fetuses of group $\mathrm{B}$ that did not survive a deep fetal acidosis was observed, with $\mathrm{pH}$ of $7.15, \mathrm{Po}_{2}$ of $3 \mathrm{~mm} \mathrm{Hg}$, and $\mathrm{Hb}$ saturation of $8 \%(P<.001)$.

In the deep hypothermia group, maternal $\mathrm{pH}$ and blood gases were in agreement with the usual reaction to hypothermia adopting the alpha-stat strategy (Table 3). The severe degree of alkalosis achieved in very deep hypothermia (Table 3), despite the fact that the alpha-stat strategy 

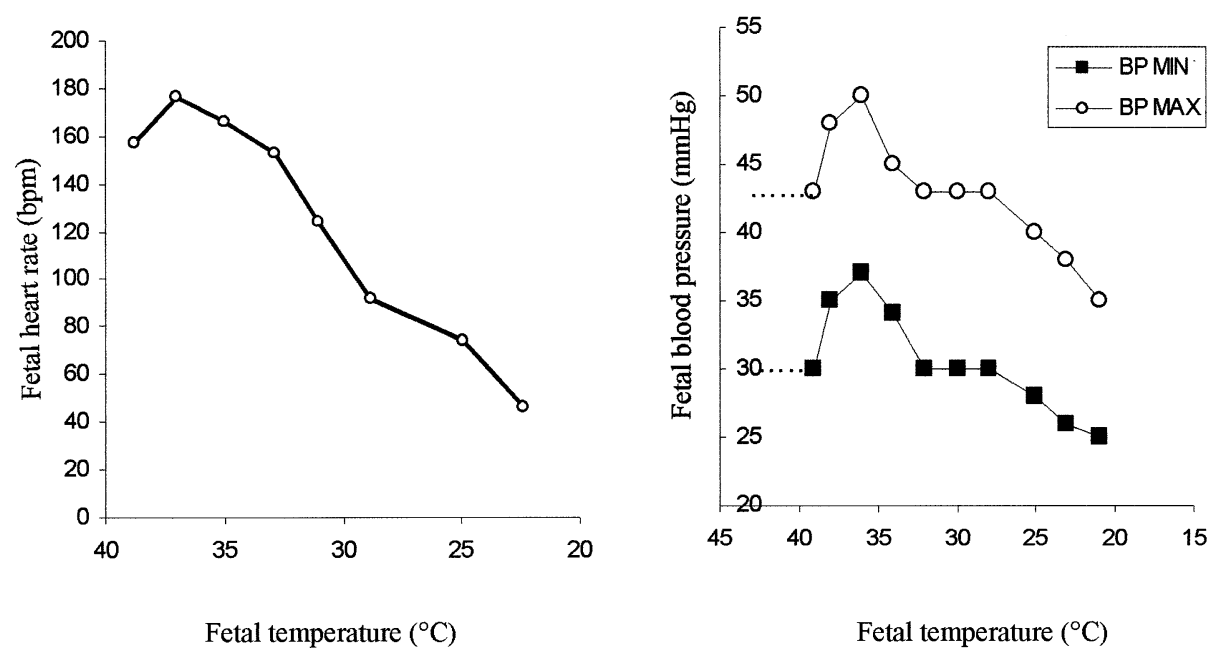

Figure 4. Relationship between fetal temperature and heart rate (left) and blood pressure (right).

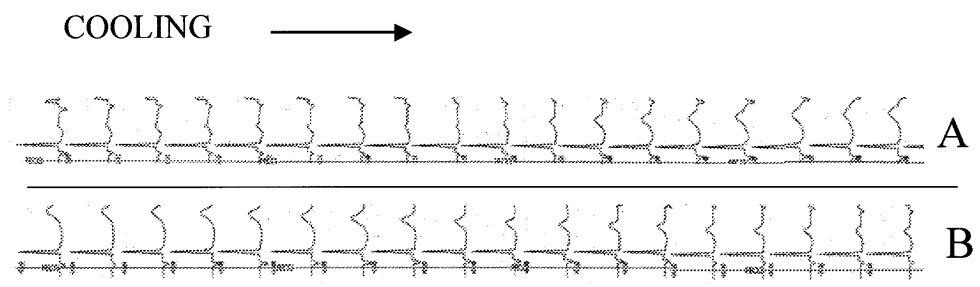

REWARMING $\longrightarrow$

Figure 5. Average of fetal ECG complexes during cooling (A) and rewarming (B).

was employed, can be partially explained with the correction of $\mathrm{pH}$ levels by the animal's temperature and to the extremely low $\mathrm{CO}_{2}$ production induced by very deep hypothermia.

\section{Discussion}

The knowledge of the fetal response to maternal CPB and hypothermia is crucial to possibly improve perinatal outcome $^{4,7,8}$ following cardiovascular surgery in pregnant women. Experimental studies on pregnant animals offer the possibility to investigate the consequences of hypothermic maternal CPB and associated anesthesiological and cardiorespiratory techniques on fetal metabolism and hemodynamics, through invasive fetal instrumentation and continuous monitoring.

In the current study we evaluated fetal survival at different levels of maternal hypothermia. Maternal temperatures at or above $18^{\circ} \mathrm{C}$, corresponding to a fetal temperature of $25^{\circ} \mathrm{C}$ or more, were associated with fetal survival and recovery after rewarming. On the contrary, lower levels of maternal cooling determined significant changes in the fetoplacental circulation leading to fetal death.
The relationship between fetal and maternal temperature showed that in all animals, independently from gestational age, fetal temperature decreased similarly during maternal cooling. We can speculate that the placenta functioned as heat exchanger with a gradient of temperature between fetus and mother in all phases of cooling. Below $20^{\circ} \mathrm{C}$ of maternal temperature, the gradient tended to increase, probably due to the reduction of both fetal cardiac output and placental flow, with a consequent decrease of placental heat exchanges. The reduction of fetal cardiac output is determined by the progressive decrease of fetal heart rate caused by the direct stimulation of cooling on the sinus node and is strictly related to fetal hypothermia: FHR decreased $7 \mathrm{bpm}$ for each degree of fetal cooling. At very low temperature, the deep fetal bradycardia and the subsequent slow diastolic depolarization phase led to a critical reduction of fetal cardiac output and of feto-placental exchanges. The fetomaternal temperature relationship was also analyzed during the rewarming phase. In the case of fetal survival, the feto-placental circulation allowed fetal rewarming following the increase of maternal temperature. During the rewarming phase the temperature gradient was inverted. On 


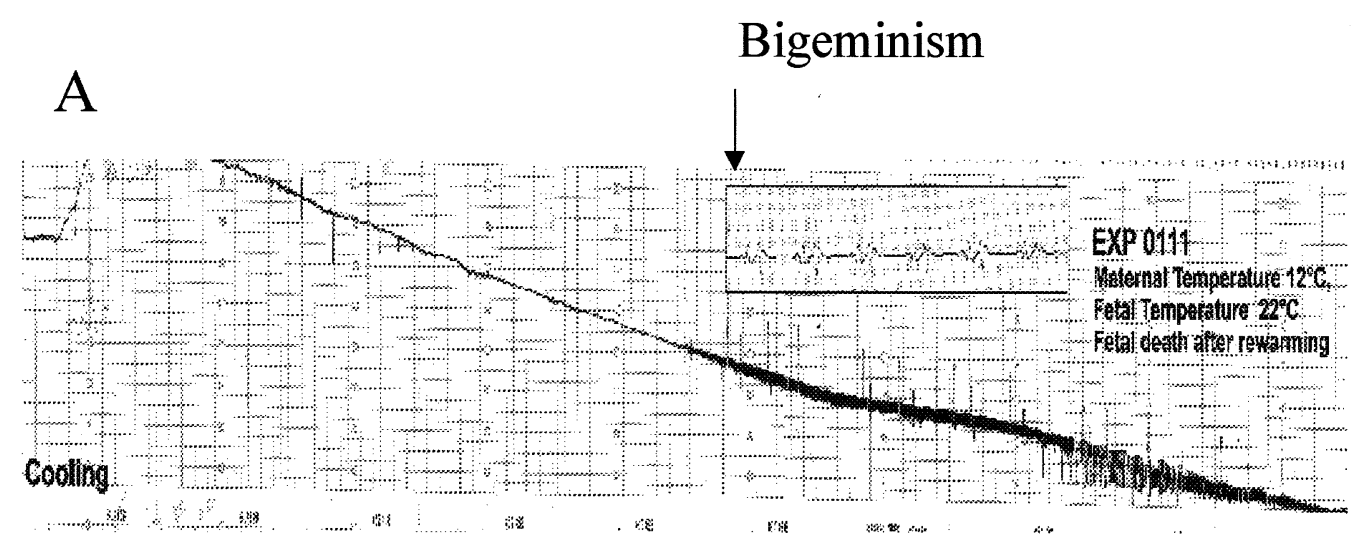

\section{B}
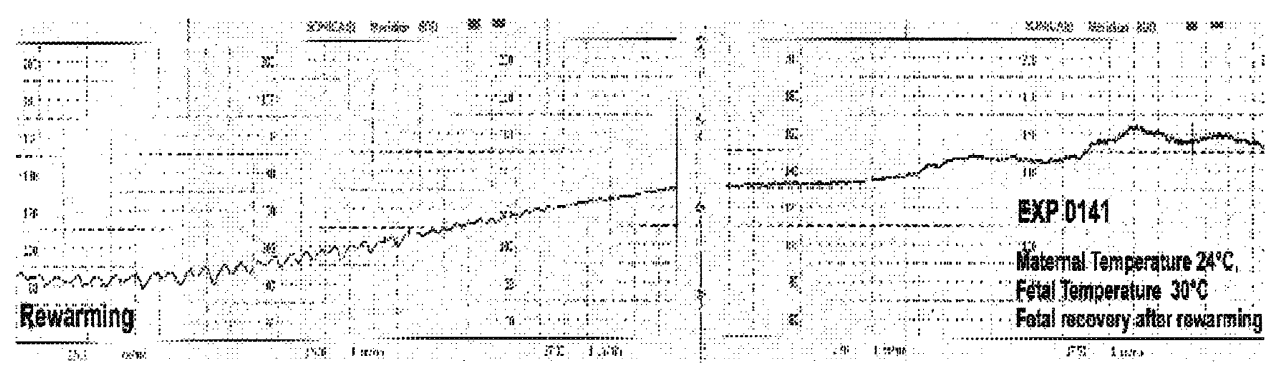

Figure 6. Fetal heart rate during cooling ( $A$, maternal temperature lowered to $12^{\circ} \mathrm{C}$ ) and rewarming (B, maternal temperature lowered to $24^{\circ} \mathrm{C}$ ).

TABLE 2. Fetal biochemical parameters at different maternal temperatures

\begin{tabular}{|c|c|c|c|c|c|c|c|c|c|c|c|c|}
\hline $\mathbf{m T}$ & $\mathbf{n}$ & fT $\left({ }^{\circ} \mathrm{C}\right)$ & pH & $\begin{array}{c}\mathrm{Po}_{2} \\
(\mathrm{~mm} \mathrm{Hg})\end{array}$ & $\begin{array}{c}\mathrm{PcO}_{2} \\
(\mathrm{~mm} \mathrm{Hg})\end{array}$ & $\begin{array}{c}\mathrm{HCO}_{3} \\
\text { (meq/L) }\end{array}$ & $\begin{array}{c}\text { Hb-sat } \\
(\%)\end{array}$ & BE (meq/L) & $\begin{array}{l}\text { Lactate } \\
\text { (mmol/L) }\end{array}$ & $\begin{array}{c}\text { Potassium } \\
\text { (mmol/L) }\end{array}$ & $\begin{array}{c}\text { Sodium } \\
\text { (mmol/L) }\end{array}$ & $\begin{array}{l}\text { Calcium } \\
\text { (mmol/L) }\end{array}$ \\
\hline \multicolumn{13}{|l|}{ Group A } \\
\hline Basal & 9 & $38.8 \pm 0.6$ & $7.34 \pm 0.1$ & $21.7 \pm 2.94$ & $47.7 \pm 2.6$ & $23.8=$ & 59 & -1 & 1.9 & 0.4 & 13 & $=0.06$ \\
\hline $24^{\circ} \mathrm{C}-20^{\circ} \mathrm{C}$ & 9 & $30.8 \pm 1.2$ & $7.39 \pm 0.1$ & $13.6 \pm 4.44$ & $42.9 \pm 8.2$ & 2 & $59 \pm 24$ & -4 & $2.9 \pm 0.9$ & $=0.5$ & 14 & 0.09 \\
\hline \multicolumn{13}{|l|}{ Group B } \\
\hline $18^{\circ} \mathrm{C}$ & 7 & $26.6 \pm 1.8$ & $7.44 \pm 0.6$ & $8.2 \pm 2.7$ & $29 \pm 10$ & $22 \pm 4.7$ & $44 \pm 2.1$ & $-4 \pm 0.2$ & $4.2 \pm 0.9$ & $2.3 \pm 0.1$ & $139 \pm 5$ & $1.5 \pm 0.1$ \\
\hline $13^{\circ} \mathrm{C}-12^{\circ} \mathrm{C}$ & 2 & $21 \pm 2$ & $7.15 \pm 0.5$ & $3 \pm 1.8$ & $46 \pm 8$ & $12.5 \pm 5$ & $8 \pm 3.5$ & $-7.5 \pm 1$ & $2.8 \pm 2$ & $3.6 \pm 1$ & $140 \pm 4$ & $1.36 \pm 2$ \\
\hline Recovery & 7 & $38 \pm 1.2$ & $7.35 \pm 0.17$ & $16.1 \pm 4.9$ & $39 \pm 11.9$ & $19.4 \pm 6.1$ & $35.3 \pm 12$ & $-4.3 \pm 5$ & $3.9 \pm 1.5$ & $3.6 \pm 0.7$ & $140 \pm 5.9$ & $91.48 \pm 0.1$ \\
\hline
\end{tabular}

$m T$, Maternal temperature; $f T$, fetal temperature; $B E$, base excess.

Data are presented as mean \pm SD.

the contrary, if the fetus did not survive, there was only an initial passive fetal rewarming due to maternal contiguity.

FHR during maternal CPB was characterized by an initial tachycardia associated with an increase of fetal blood pressure immediately following the start of CPB and cooling; this was probably due to a fetal catecholaminergic stress response and to the change of the maternal blood flow from pulsatile to linear. ${ }^{1,6,7}$ Then, FHR progressively decreased until a level of very deep bradycardia ${ }^{12}$ that could be tolerated only when maternal temperature did not fall below $18^{\circ} \mathrm{C}$. In these cases, rewarming led to a gradual return of FHR to normal values.
Changes of ST interval observed in fetal ECG during cooling can depend on adrenergic stimulation and reduction of arterial $\mathrm{PO}_{2}$ as previously described in the human fetus. ${ }^{18}$ Ventricular bigeminism can be due to a direct effect of hypothermia on the sinus node and the conducting cardiac fibers.

Fetal metabolic and blood gases data suggest that the fetus tolerates well maternal hypothermia at or above $20^{\circ} \mathrm{C}$. At this temperature the reduction of fetal $\mathrm{Po}_{2}$ is well compensated by the left shifting of $\mathrm{Hb}$-saturation curve, leading to normal oxygen saturation. At the same time a decrease of fetal $\mathrm{PCO}_{2}$ is observed as a consequence of the reduced 
TABLE 3. Maternal biochemical parameters at different temperatures

\begin{tabular}{|c|c|c|c|c|c|c|c|c|c|c|c|}
\hline mT & $\mathbf{n}$ & pH & $\begin{array}{c}\mathrm{Po}_{2} \\
(\mathrm{~mm} \mathrm{Hg})\end{array}$ & $\begin{array}{c}\mathrm{PcO}_{2} \\
(\mathrm{~mm} \mathrm{Hg})\end{array}$ & $\begin{array}{c}\mathrm{HCO}_{3} \\
\text { (meq/L) }\end{array}$ & $\begin{array}{c}\text { Hb-sat } \\
(\%)\end{array}$ & $\begin{array}{c}\mathrm{BE} \\
(\mathrm{meq} / \mathrm{L})\end{array}$ & $\begin{array}{l}\text { Lactate } \\
\text { (mmol/L) }\end{array}$ & $\begin{array}{c}\text { Potassium } \\
\text { (mmol/L) }\end{array}$ & $\begin{array}{l}\text { Sodium } \\
\text { (mmol/L) }\end{array}$ & $\begin{array}{l}\text { Calcium } \\
\text { (mmol/L) }\end{array}$ \\
\hline \multicolumn{12}{|l|}{ Group A } \\
\hline Basal & 9 & $7.45 \pm 0.07$ & $175 \pm 124$ & $36.8 \pm 8$ & $25.8 \pm 2$ & $99 \pm 3$ & $0.6 \pm 2$ & $1.6 \pm 1$ & $4 \pm 0.4$ & $145 \pm 3$ & $1 \pm 0.1$ \\
\hline $24^{\circ} \mathrm{C}-20^{\circ} \mathrm{C}$ & 9 & $7.57 \pm 0.07$ & $321 \pm 201$ & $25 \pm 14$ & $26 \pm 1.9$ & $104 \pm 1$ & $-2.3 \pm 1$ & $1.6 \pm 0.9$ & $2.8 \pm 0.5$ & $114 \pm 2.1$ & $1 \pm 0.1$ \\
\hline \multicolumn{12}{|l|}{ Group B } \\
\hline $18^{\circ} \mathrm{C}$ & 7 & $7.45 \pm 0.07$ & $362 \pm 108$ & $20 \pm 9$ & $24 \pm 1.9$ & $103 \pm 1$ & $-2.7 \pm 2$ & $2 \pm 0.9$ & $3.1 \pm 0.5$ & $143 \pm 5$ & $0.9 \pm 0.1$ \\
\hline $13^{\circ} \mathrm{C}-12^{\circ} \mathrm{C}$ & 2 & $7.72 \pm 0.09$ & $312 \pm 170$ & $14 \pm 7$ & $25 \pm 3$ & $103 \pm 4$ & $-2.9 \pm 0.4$ & $1.4 \pm 1$ & $5 \pm 0.6$ & $143 \pm 7$ & $1 \pm 0.8$ \\
\hline Recovery & 7 & $7.54 \pm 0.05$ & $145 \pm 85$ & $23 \pm 5$ & $24.8 \pm 1.4$ & $98 \pm 4$ & $-2.7 \pm 2$ & $3.1 \pm 0.5$ & $3.5 \pm 0.5$ & $143 \pm 4.6$ & $1.2 \pm 0.3$ \\
\hline
\end{tabular}

$m T$; Maternal temperature; $B E$, base excess.

Data are presented as mean \pm SD.

metabolism. Mild fetal alkalosis occurs as expected during hypothermia adopting the alpha-stat strategy. These fetuses return to normal blood gases and $\mathrm{pH}$ values after rewarming. At lower levels of maternal cooling $\left(18^{\circ} \mathrm{C}\right)$, the fetus survives but the alterations of blood gases and acid-base balance are not associated with a good perinatal outcome. Undoubtedly very deep maternal hypothermia (under $14^{\circ} \mathrm{C}$ ) causes a progressive reduction of fetal $\mathrm{Po}_{2}$, oxygen saturation, and $\mathrm{pH}$ leading to fetal death, probably consequent to a profound and irreversible reduction of villous fetal flow. However, an alternative explanation for the reduced placental oxygen exchange is the reduction in uterine placental perfusion consequent to the alkaline $\mathrm{pH}$, as well as the reduction in oxygen delivery consequent to the low maternal hematocrit, ${ }^{19,20}$ which may have been important factors contributing to the decreased placental oxygen exchange. ${ }^{21}$ Higher hematocrits could result in improved placental oxygen availability and lead to better fetal outcomes. This possibility should be considered in future studies using the alternative $\mathrm{pH}$-stat strategy.

In conclusion, maternal hypothermic CPB not lower than $20^{\circ} \mathrm{C}$ is associated with fetal survival and recovery without significant modifications in fetal blood oxygenation and acid-base balance. The fetal response to this condition reflects a reversible situation that can be compensated. Deeper hypothermia leads to a progressive fetal cardiovascular and metabolic derangement that cannot be tolerated by the fetus. The data presented in this experimental trial improve the knowledge about fetal response to maternal hypothermic CPB during cardiovascular surgery, providing important information to surgeons and perinatologists. These data could also provide a basis for the possibility of in utero cardiac surgery after the induction of fetal hypothermia through the mother.

\section{References}

1. Arias F. Cardiac disease and pregnancy. In: Arias F, editor. High-risk pregnancy and delivery. St Louis: Mosby Year Book; 1993. p. 312-29.

2. Tripp HF, Stiegel HM, Coyle JP. The use of pulsatile perfusion during aortic valve replacement in pregnancy. Ann Thorac Surg. 1981;67: 1169-71.

3. Bernal JM, Miralles PJ. Cardiac surgery with cardiopulmonary bypass during pregnancy. Obstet Gynecol Surv. 1986;41:1-6.

4. Levy D, Warriner RA, Burgess GE. Fetal response to cardiopulmonary by-pass. Obstet Gynecol. 1980;56:112-5.

5. Chambers CE, Clark SL. Cardiac surgery during pregnancy. Clin Obstet Gynecol. 1994;37:316-26.

6. Souza MHL, Decio OE. Cardiopulmonary bypass in pregnant patients. Pregnancy and Cardiopulmonary Bypass. 2001;10:1-18.

7. Pomini F, Mercogliano D, Cavalletti C, et al. Cardiopulmonary bypass in pregnancy. Ann Thoracic Surg. 1996;61:259-68.

8. Weiss B, von Segesser L, Alon E, et al. Outcome of cardiovascular surgery and pregnancy: a systematic review of the period 1984-1996. Am J Obstet Gynecol. 1998;179:1643-53.

9. Mahli A, Izdes S, Coskun D. Cardiac operations during pregnancy: review of factors influencing fetal outcome. Ann Thorac Surg. 2000; 69:1622-6.

10. Assali NS, Westin B. Effects of hypothermia on uterine circulation and on the fetus. Proc Soc Exp Biol Med. 1962;109:485-8.

11. Westin B, Sehgal N, Assali NS. Regional blood flow and vascular resistance during hypothermia in dog. Am J Physiol. 1961;201:481-5.

12. Jadhon M, Main EK. Fetal bradycardia associated with maternal hypothermia. Obstet Gynecol. 1998;72:496-7.

13. Barbera A, Jones OW 3rd, Zerbe GO, Hobbins JC, Battaglia FC, Meschia G. Ultrasonographic assessment of fetal growth. Comparison between human and ovine fetus. Am J Obstet Gynecol. 1995;173:1765-9.

14. Swain JA. Hypothermia and blood pH. Arch Intern Med. 1998;148: 1643-8.

15. Lilija H, Arulkumaran S, Lindecrantz R, Rosen KG. Fetal ECG during labour: a presentation of a microprocessor system. J Biomed Eng. 1998; 10:348-50.

16. Pardi G, Cetin I, Marconi AM, et al. Diagnostic value of blood sampling in fetuses with growth retardation. $N$ Engl J Med. 1993;328: 692-6.

17. Trevino A, Razi B. The characteristic electrocardiogram of accidental hypothermia. Arch Intern Med. 1971;127:470-3.

18. Pardi G, Tucci E, Uderzo A, Zanini D. Fetal electrocardiogram changes in relation to fetal heart patterns during labour. Am J Obstet Gynecol. 1974;118:243-50.

19. Shin'oka T, Shum-Tim D, Jonas RA, et al. Higher hematocrit improves cerebral outcome after deep hypothermic circulatory arrest. J Thorac Cardiovasc Surg. 1996;112:1610-20.

20. Shin'oka T, Shum-Tim D, Laussen PC, et al. Effects of oncotic pressure and hematocrit on outcome after hypothermic circulatory arrest. Ann Thorac Surg. 1998;65:155-64.

21. Sakamoto T, Zurakowski D, Duebener LF, et al. Combination of alpha stat strategy and hemodilution exacerbates neurologic injury in a survival piglet model with deep hypothermic circulation arrest. Ann Thorac Surg. 2002;73:180-9. 